\title{
Effective Electronic Human Resource Management For Educational Institutions
}

\author{
L. Amudha ${ }^{1}$, I. Infant Raj ${ }^{2}$, T.M. Nithya ${ }^{3}$ \\ K.Ramakrishnan College of Engineering, Samayapuram, Trichy ${ }^{1,2,3}$
}

\begin{abstract}
For any organization may it be a school, college, hospital, industry or any organization, the major task is to identify the roles and responsibilities of individuals in the organization. Earlier details are maintained as hard coded handwritten ledgers and documents which were difficult and cumbersome in maintenance and verification. In the Recent years, many companies have transformed to digital method of handling employee information. This paper discusses about one such digital maintenance with the need for digitization and benefits. The effective way of implementation is also discussed with relevant screen captures.
\end{abstract}

Keywords: Digitization, Employee, Organization, Business, Retention, Analytics

\section{INTRODUCTION}

Selecting, employing and training the right people for right job is a key role in a HR management policy.The HR management can be defined as a set of 7 phases: Recruitment, On-boarding, Attendance maintenance, Payroll processing, Appraisals, Training and Exit. Any employee of an organization goes through these 7 stages while employed in the organization. For effective process in each of these stages, detailed analysis and implementation method is needed.

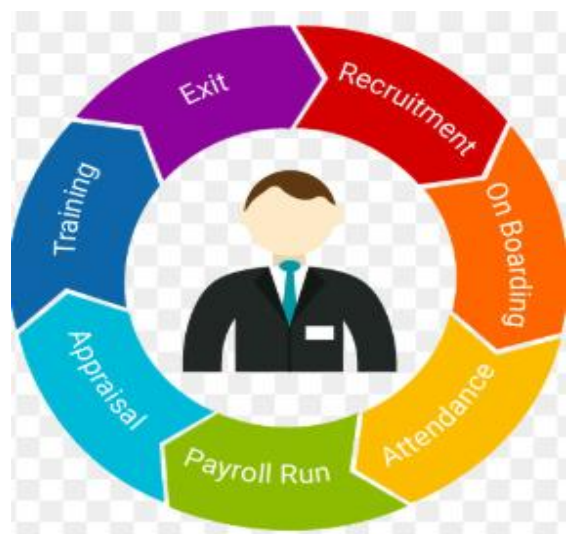

Fig. 1. Phases of HR Management life cycle

\section{RESOURCES OF AN INSTITUTION}

Resources of an institution or company may be production raw materials, inventory items, financial resources, hardware, (licensed) software, venue, vehicle(s), network bandwidth, water supply, electricity, food commodities, equipments, support systems and so on. But for any kind of job, mandatory resource is obviously going to be human requirement. Any business cannot be run without human intervention. Even fully automated projects need human assistance and monitoring for proper functioning. So it is an essential and necessary thing to manage the human resources in a best way.

\section{NEED FOR HUMAN RESOURCE MANAGEMENT}

Management of human resources is a skill, and if done manually, it would be error prone and it is going to be a time consuming task. Hence it is most required for every small to large organizations to shift to digital method of maintaining employee information. Digitization is a huge transformation in many organizations. It paves way for talent identification and allotment of responsibilities and duties[1]. Digitization also provides a method to inspect the effective utilization of the human resource in terms of working time, number of leaves, permissions in monthly or 
annual basis. Any digital transformation is headed by a HR Any issues and challenges in human resource management must be sorted out and solved before it causes any obstacle in the normal working of an organization.

\section{NEED FOR DIGITAL METHOD OF HRM}

Enthusiasm and creativity of an individual is more important. Organizations that are transparent in its all activities gives the employee trust and faith over the employer. Digitization makes things more transparent. Every task undergoes a series of fixed steps. Any approval goes through proper hierarchy in the organization. When these are added up with timely incentives and awards encourages the individual for individual growth. This in turn will increase the rate of employee retention. Employee retention helps to reduces the turn over rate of an organization.

\section{IMPLEMENTATION}

One such digital method of employee management system is shown in the following snapshots. Effective usage of such digital methods would induce growth in both the organization and employee.

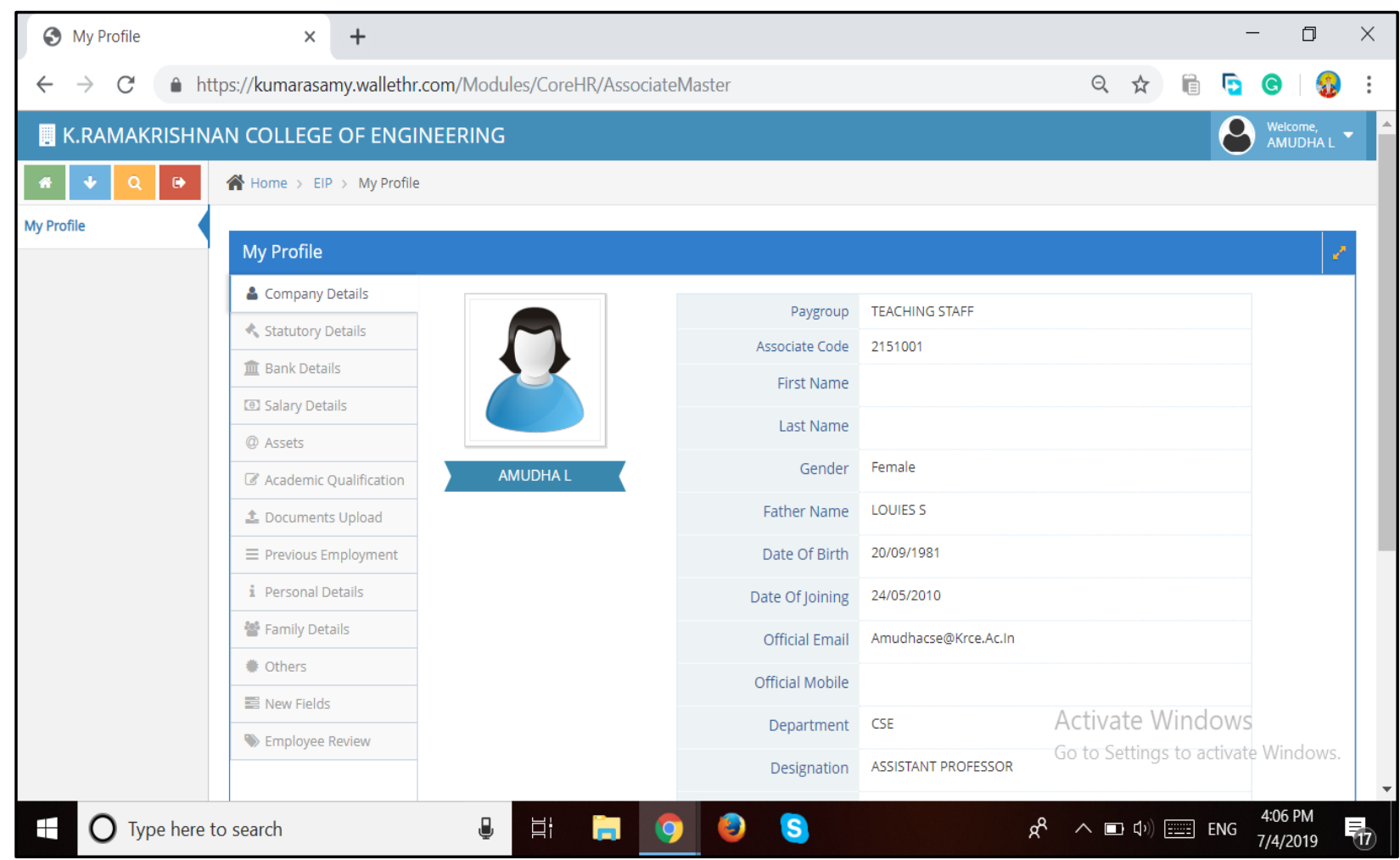

Fig.2 Employee basic information

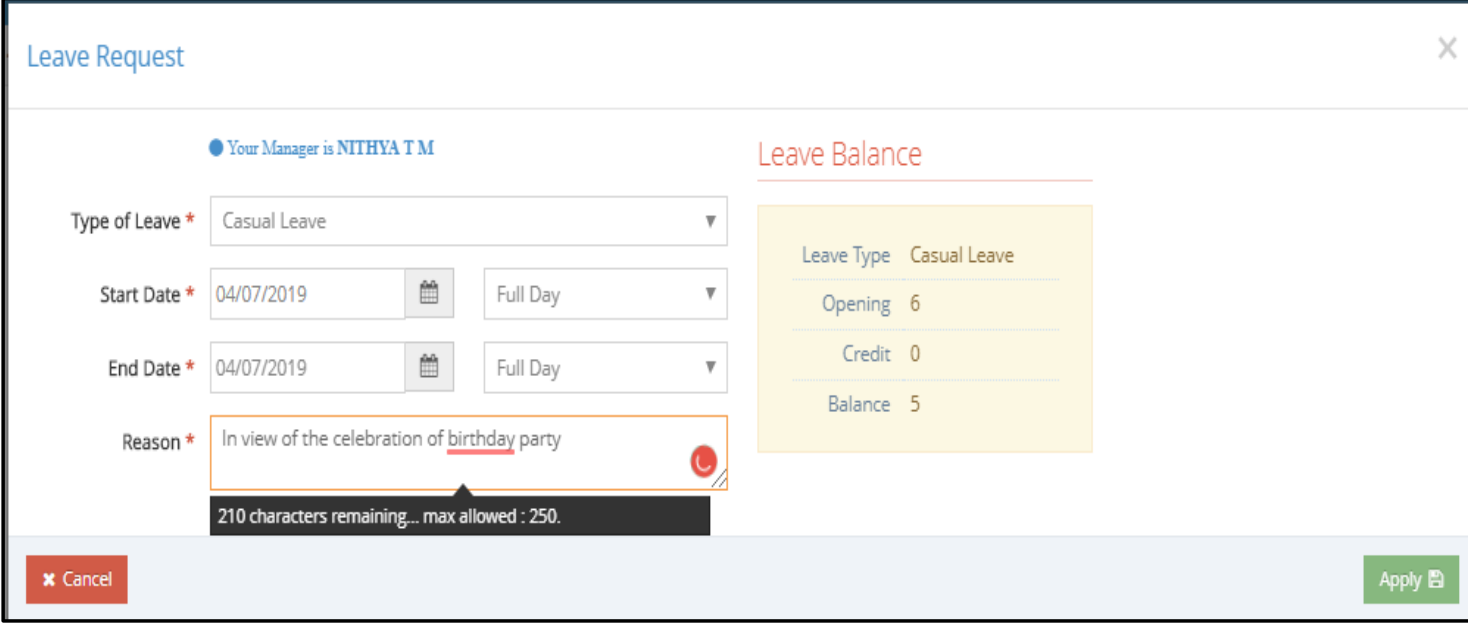

Fig.3 Leave request submission to the immediate higher authority 


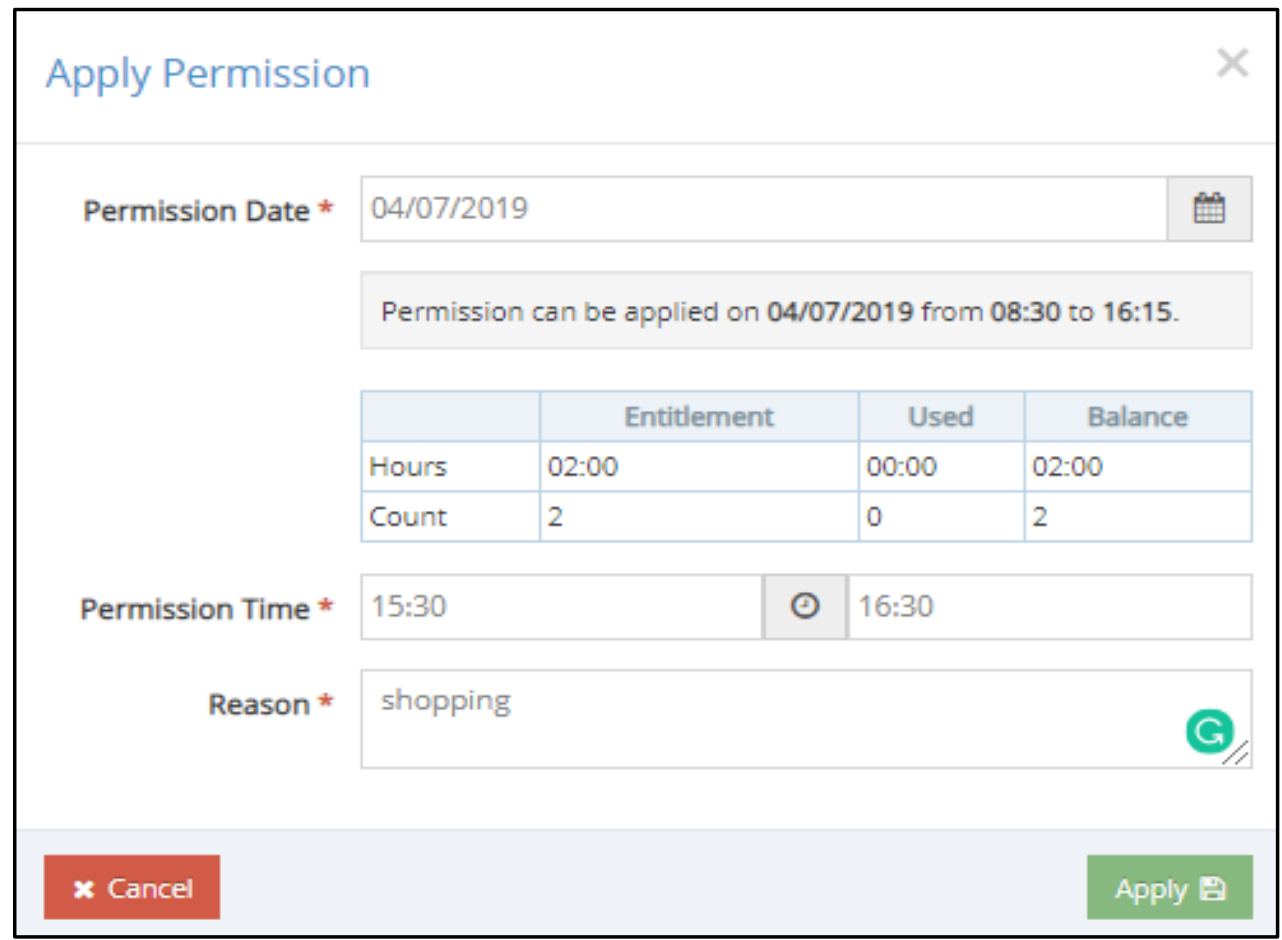

Fig.4 Permission request with available balance number of permissions

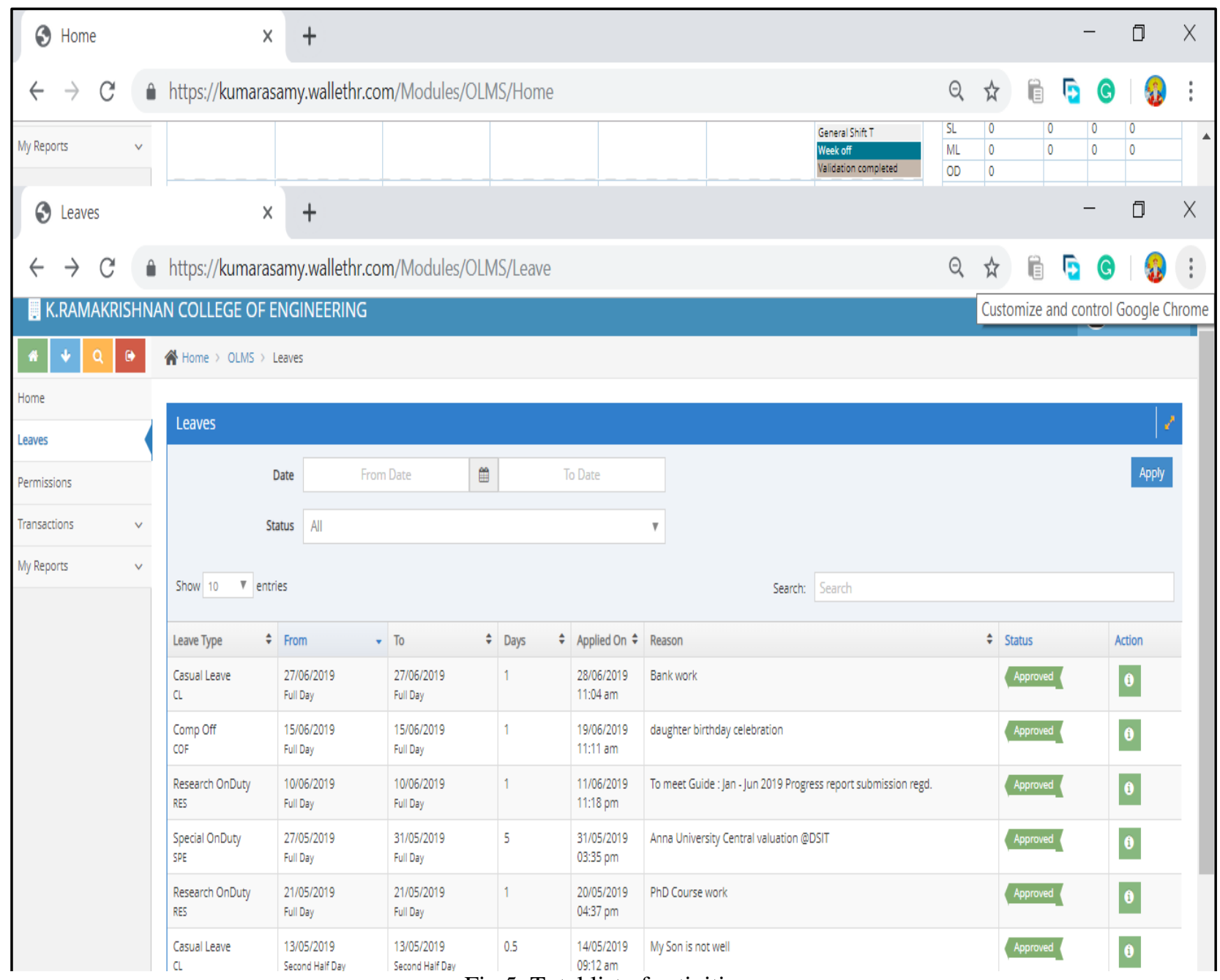

Fig 5. Total list of activities 
Vol. 8, Issue 6, June 2019

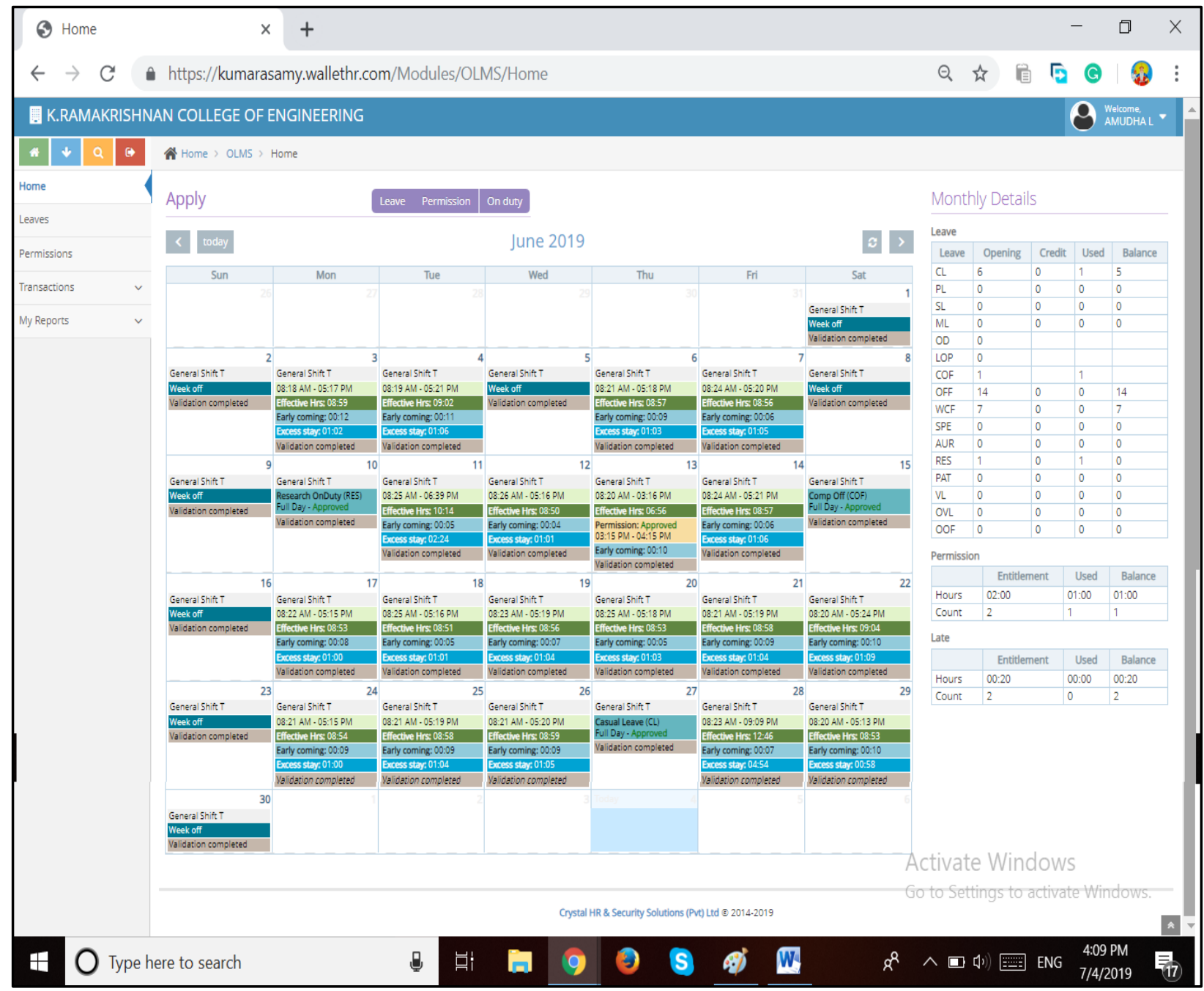

Fig.6 One month consolidated in-out details of an employee.

\section{CONCLUSION AND FUTURE SCOPE}

The digital information provides a way to perform analytics over the faculty information. Historical and time-series data is maintained as a collection of records and databases. In the near future, these data could be used to generate useful insights for the betterment of individual employee and the organization as a whole. Further, technologies like parallel processing[3], machine learning, deep learning with modern programming languages and tools such as Python and $\mathrm{R}$ effective and quick analysis can be done. Keeping the future perspective, decisions can be done by the administrative team efficiently.

\section{REFERENCES}

[1]. Business and Information Management, International Seminar on Research of the Human Resource Management in Enterprise Based on the Innovative Incentive Year: 2008, Volume: 2, Pages: 445-448, DOI Bookmark:10.1109/ISBIM.2008.160

[2]. Strategic human resource management, human capital and competitive advantage: is the field going in circles? John E. Delery and Dorothea Roumpi, Department of Management, Sam M. Walton College of Business, University of Arkansas Human Resource Management Journal, Vol 27, no 1, 2017, pages 1-21

[3]. "Tapping the Full Potential of Multicore on Intelligent Machines with Parallel Algorithms", Amudha L, NithyaT.M , Infant Raj I, International Journal of Latest Technology in Engineering, Management \& Applied Science Volume 7, Issue VI, pp 125-128 